\title{
Homing and space activity in bank voles Clethrionomys glareolus
}

\author{
Roman ANDRZEJEWSKI, Joanna BABIŃSKA-WERKA, Anna LIRO, \\ Edyta OWADOWSKA and Jakub SZACKI*
}

\begin{abstract}
Andrzejewski R., Babińska-Werka J., Liro A., Owadowska E. and Szacki J. 2000. Homing and space activity in bank voles Clethrionomys glareolus. Acta Theriologica 45: 155-165.

Spatial activity and homing of bank voles Clethrionomys glareolus (Schreber, 1780) have been studied in the 100 years old alder wood (Carici elongatae-Alnetum Koch, 1926) in the Kampinos National Park near Warsaw. Six parallel trap lines of $600 \mathrm{~m}$ each were set. Each of external lines consisted of 100 live-traps. Between the two lines, 4 lines of 200 snap-traps in each were set at $100 \mathrm{~m}$ intervals. Individuals caught in live-traps were individually marked and released in the centre of the study area. During the study 613 bank voles were marked and 424 recaptures were recorded. Considerable mobility of animals was found (a high proportion of animals moved more than $600 \mathrm{~m}$ ). Distribution of animals retrapped made it possible to determine hypothetical spatial patterns of homing. It is suggested that familiarity with the given area acquired during long distance movements help small mammals to find their way when homing regardless of the nature of homing.

Catholic University of Lublin, Al. Racławickie 14, 20-950 Lublin, Poland (RA); Department of Game Management, Agriculture University of Warsaw, Rakowiecka 26/30, 02-528 Warsaw, Poland (JB-W); Kampinos National Forest, Tetmajera 38, 05-080 Izabelin, Poland (EO); National Foundation for Environment Protection, Krzywickiego 9, 02-078 Warsaw, Poland (AL, JS)

Key words: Clethrionomys glareolus, homing, spatial activity
\end{abstract}

\section{Introduction}

Bovet (1992) has reviewed the existing knowledge of homing in mammals, including rodents. He presented three basic hypotheses for explaining the capability of individuals in finding home ranges when displaced experimentally to various distances. Finding a home range may be due to: (1) random searching for the home range (while penetrating the area after release), (2) familiarity with the area between release site and home range, and (3) innate capability of animals to find their home ranges by navigation. The order of the three hypotheses is consistent with increasing complexity of explanation of animal returns to home ranges. The latter hypothesis leads to search for physiological "compasses" used by animals

* Present address: Mandarynki 10 m. 25, 02-796 Warsaw, Poland 
while homing (Bovet 1992 and references therein). Bovet (1992) and other authors suggest that an animal returning home actually may not necessarily head to the home range but to a much more extensive "life range". However, that term is not sufficiently defined and it does not produce methodological bases for empirical delimitation in the field.

Another phenomenon, rarely found by students of animals, is catching individuals far from their home ranges determined on the basis of earlier multiple catches. Such cases are explained as occasional "sallies" or "excursions" outside usual home ranges (Gashwiler 1959, Ilienko and Zubchaninova 1963, Stickel 1968, Furrer 1973, Joslin 1977, Bovet 1992). For some time several papers have been published suggesting that in fact rodent home ranges are not small. "Sallies", earlier recognized as occasional events, appeared to be normal behaviour of small mammals (Crawley 1969, Andrzejewski and Babińska-Werka 1986, Lidicker and Patton 1987, Liro and Szacki 1987, Clark et al. 1988, Tew 1988, Szacki and Liro 1991, Szacki et al. 1993, Liro and Szacki 1994, Kozakiewicz and Szacki 1995, Szacki 1999). Thanks to their mobility rodents are able to find promptly a new food source appearing in the field (Babińska-Werka 1990a, b).

Data indicating an extensive range of movements suggest that a small home range is a methodological artifact resulting from the presence of a grid of live-traps. It makes necessary a re-interpretation of results of many studies of small mammal ecology that use CMR and small grids of traps (Andrzejewski and Babińska-Werka 1986). For example, the distinction between sedentary and migrating parts of a population (Rall 1936 and a great body of later information), estimation methods for small mammal density especially developed during the International Biological Programme (Grodziński et al. 1966 and others) and the theory of territoriality of adult bank vole females (Bujalska 1973, 1985, 1988, 1990) should be critically reviewed. Also, the theory of homing should be revised since displacement of an animal at a distance of a few hundreds or even over $1000 \mathrm{~m}$ from the site of capture may still take place within the area of usual movements of small mammals.

We should go back to the old hypothesis that individuals, displaced some distance from their capture sites, find a group of traps set in a small grid where they had been caught previously because they use information about familiar routes between release and capture sites (Murie and Murie 1931, Robinson and Falls 1965, Fisler 1967, Anderson et al. 1977) although, irrespectively of the hypothesis assumed, considerable mobility of rodents may increase their homing success. Common occurrence of long distance movements among small mammals means also that a consdiderable proportion of their movements are usually not covered by trap grids of a standard size.

The aim of our study was to assess homing and generally spatial mobility of bank voles Clethrionomys glareolus (Schreber, 1780) in relation to information indicating long range movements. Also, we attempted at finding possible movement patterns of bank voles basing on trapping data and their hypothetical movements outside our grid of traps. 


\section{Material and methods}

The study was carried out in Kampinos National Park, some $30 \mathrm{~km}$ west of Warsaw. The study ares was located in relatively homogenous habitat of alder wood aged app. 100 years, belonging to the plart community Carici elongateae-Alnetum (Koch, 1926).

Six lines of traps (A, B, C, E, F, and G) $600 \mathrm{~m}$ long were set at $100 \mathrm{~m}$ intervals (the distance was $200 \mathrm{~m}$ between $\mathrm{C}$ and $\mathrm{E}$ lines only; Fig. 1). A and G lines consisted of 100 wooden live-traps set at $6 \mathrm{~m}$ intervals. Each of lines B, C, E and F consisted of 200 snap-traps at $3 \mathrm{~m}$ intervals. So, lines of live- and snaj-traps formed a square of 36 ha. Snap-traps were used to obtain data on return routes of indviduals caught in live-traps in lines within the square. The use of live-traps on all the lines would have resulted in permanently interfering with individuals traveling across the study area, and severely biasing the picture of their spatial activity.

Live-traps were set on lines and not in a grid as we assumed that lines influence movements of small mammals to a lesser degree than a grid of many traps. Using two lines ("eastern" and "western") on spposite sides of the release point was needed to determine homing abilities of small mammals uncer study. "Northern" and "southern" lines of traps were not set to avoid a complicated geometrical arrangement of bank vole caughts. Arrangement of traps in a way they would formed concentric figures was impossible in a dense forest without cutting many trees and bushes and the study area was locted in a national park.

The bait in live-traps consisted of oat grains. Snap-traps were provided with two types of bait: (1) plastic sponge soaked with sunflower oil and (2) similar sponges with the odour of bank voles from the laboratory (Andrzejewski and Owadowska 1994). Snap-traps containing oil bait were set on the first halres of B and C lines (traps numbered 1-100) and on the second halves of E and F lines (traps 101-200). The remaining traps were provided with bait containing bank vole odour. Thus, we have obtained a pattern of four quadrates to compare results of catching in traps containing different baits (Fi६. 1). Two different types of bait allowed for addressing the question whether one of them reveals more return routes than another.

Rodents were trapped in September 1994, for 14 days. Traps were checked once daily, in the moming. Individuals caught in live-traps were marked by toe-clipping. Species, sex and place of capure were recorded for every animal caught. Animals were released in the centre $(R)$ of the study are (Fig. 1). In the case of rodents caught in snap-traps, their number (if previously caught in

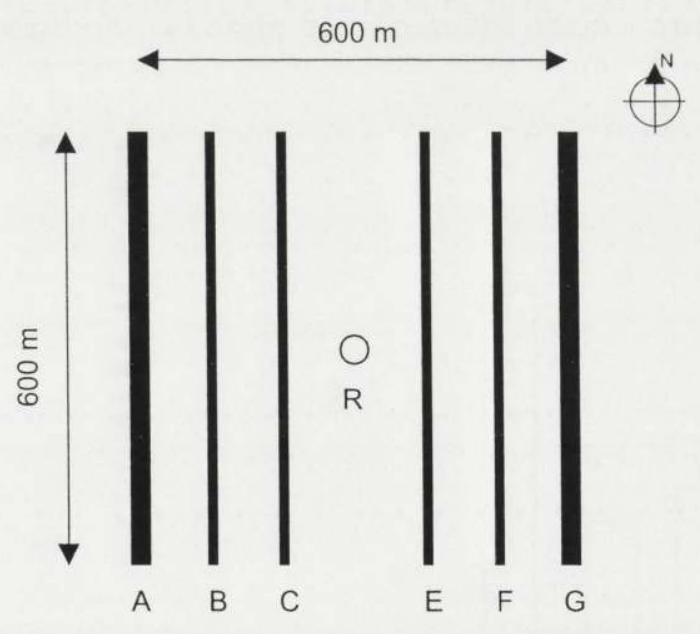

Fig 1. The arrangement of trap lines and the central point $\mathrm{R}$ of release. A and $\mathrm{G}$ - lines of live-traps; B, $\mathrm{C}, \mathrm{E}, \mathrm{F}$ - lines of snap-traps. 
live-traps), sex, and number of trap station were recorded. Rodents caught in snap-traps were dissected to check for breeding condition (position of testes, implantation scars, presence of embryos, lactation) The population was relatively homogenous in terms of sexual activity (after breeding season) and in terms of age structure (most individuals had been born in the summer 1994).

During the study, a total of 1230 bank voles were caught including 613 individuals caught in live-traps. Besides, a few individuals of Apodemus flavicollis, A. agrarius, Micromys minutus, and Microtus agrestis were also caught. They were not subject to any further analysis.

\section{Results}

\section{Numbers of bank voles caught in live-traps and snap-traps}

We have compared average number of voles caught per day in live-traps and snap-traps, separately for lines located far from and close to the central point $R$. It was found that the average number of catches of bank voles per day was greatest on lines of live-traps (line A: $\bar{x} \pm \mathrm{SE}=37.0 \pm 2.9$, line $\mathrm{G}: 31.7 \pm 2.3$ ) and the lowest on lines of snap-traps adjacent to the lines of live-traps (line B: $9.8 \pm 2.5$, line F: $8.5 \pm$ 1.8). All differences are statistically significant (Student's $t$-test for paired dependent sample: $p<0.05$ ). More bank voles per day were caught on the lines of snap-traps located in the vicinity of the central point $R$ (Fig. 2). On average, significantly more bank voles were caught per day in traps with bank vole odour $(30.2 \pm 10.2)$ than in traps with sunflower oil bait $(17.3 \pm 4.9)$ (the same $t$-test: $p<0.001$ ).

Unmarked animals were caught in live-traps throughout the whole experiment. Then they were released at the central point (R), along with recaptured voles. In total, 613 bank voles were marked during the live-trapping, 391 of them $(64 \%)$ were not re-trapped after releasing, $117(19 \%)$ were live-trapped one or more times after releasing and $105(17 \%)$ were caught directly in snap-traps after release. Nine (of 117) individuals were caught in snap-traps after two or three visits to live-traps (Table 1).

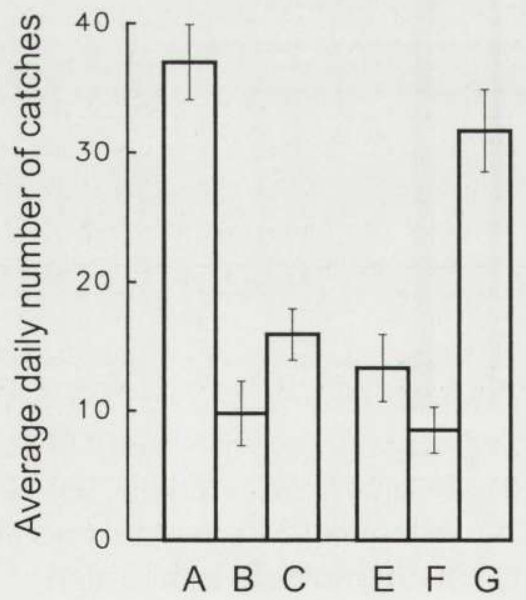

Fig. 2. Average daily number of catches on particular lines of live-traps (A and G) and snap-traps (B, C, E, F). Fine lines on bars denote SE. 


\begin{tabular}{|c|c|c|}
\hline $\begin{array}{l}\text { Successive catches } \\
\text { of marked bank voles }(n)\end{array}$ & a & $\mathrm{b}$ \\
\hline 1 & 42 & 105 \\
\hline 2 & 27 & 7 \\
\hline 3 & 14 & 2 \\
\hline 4 & 12 & - \\
\hline 5 & 14 & - \\
\hline 6 & 3 & - \\
\hline 7 & 4 & - \\
\hline 8 & 1 & - \\
\hline Total number of individuals & 117 & 114 \\
\hline Total catches & 310 & 114 \\
\hline
\end{tabular}

\section{Recaptures in live-traps}

The experiment revealed four patterns of spatial behaviour of bank voles caught in a certain live trap (C1) and released in the central point R (Fig. 3): pattern I when a bank vole was re-trapped (in $\mathrm{C} 2$ ) on the same trap line close to the first catch (C1), pattern II - when a bank vole was re-trapped on the same trap line but far from the first catch, patterns III and IV - when a bank vole was re-trapped on the opposite live trap line.

The distribution of numbers of animals that were caught in different locations on the live-trap lines when caught for the first and the second time shows that only $40 \%(n=117)$ of individuals were caught for the second time within the same half of a trap line (Fig. 4, pattern I), that is, rather close to the place of first capture (distance delimited by 50 traps, that is, shorter than $300 \mathrm{~m}$ ). Fifteen percent of animals were caught for the second time on the other half of the line (pattern II). Thus, only $55 \%$ of individuals were caught the first and the second time on the same line. Sixteen percent of bank voles were caught for the second time on the opposite live-trap line in the same half (either northern or southern), that is at a distance of over $600 \mathrm{~m}$ (Fig. 4, pattern III). A considerable portion of individuals (29\%) were caught for the second time on the opposite live trap-line, but on the different half, that is at a distance of more than $600 \mathrm{~m}$ from the first catch (Fig. 4, pattern IV).

The distribution of catches was different when distances between the second and third catches were analyzed $(n=75)$. In as many as $90 \%$ of cases the animals were caught within the same half of the same line and only $5 \%$ in another half of the same line. When third and fourth catches $(n=52)$ are taken into account, $94 \%$ of voles were caught in the same half of the same line. All bank voles caught for the fifth or more time $(n=66)$ were recorded in the same half of the same line. 
A

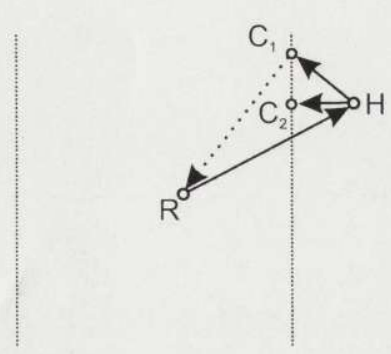

| "out"

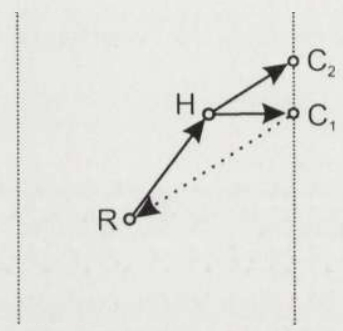

I "in"
A

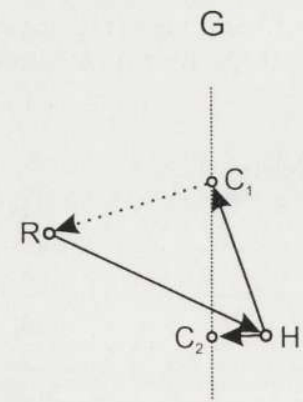

II "out"

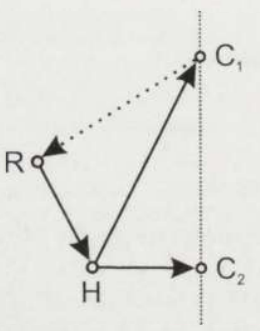

II "in"
A

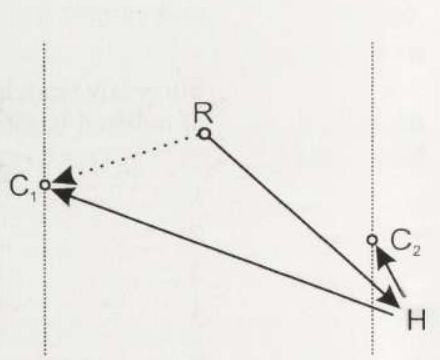

III, IV "out"

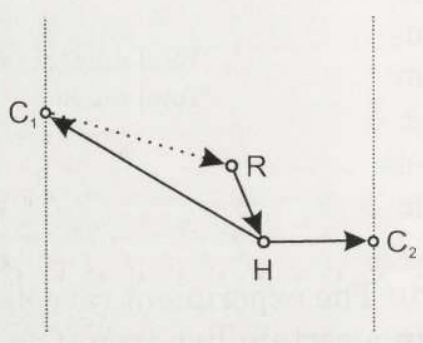

III, IV “in”

Fig. 3. Hypothetical distances between subsequent catches. H - individual "home"; C1, C2 - places of subsequent catches; R - release point in the centre between A and G (lines of live-traps); "in" means that $\mathrm{H}$ is between $\mathrm{A}$ and $\mathrm{G}$ and "out" that $\mathrm{H}$ is outside the belt between $\mathrm{A}$ and $\mathrm{G}$. Two subsequent catches could be consistent with: pattern I - distance shorter than a half of a live trap line; pattern II distance longer than a half of the same trap line; pattern III - catches in the same half (southern or northern), on two opposite trap lines; pattern IV - catches in different halves, on two opposite trap lines.

Two conclusions may be drawn from the above data: (1) a large proportion of bank voles were caught for the second time at a considerable distance from the first one; (2) subsequent catches of bank voles are closer and closer to the previous one.

The second conclusion is also illustrated by the analysis of linear distances between traps where individuals were caught for the first and the second time, the second and the third one, etc, on the same live-trap line. It was found that the larger the number of catches, the shorter was the distance between them (Table 2).

The frequency of capturing the same individuals in live-traps was also analyzed. In order to do so, the average number of days between the first and the second, the second and the third, etc, capture in live-traps was calculated. It was found that the period between the consecutive catches was decreased, tending to every-day catches. After the first release only $3 \%(n=117)$ of individuals were captured for the second time as soon as the next day. Between the second and the third capture 
Fig. 4. Proportion of catches in live-traps and snap-traps consistent with different patterns of catching. I, II, III, IV - different patterns of catching (see text for explanation); black bars denote catches in live-traps, white bars denote catches in snap-traps.

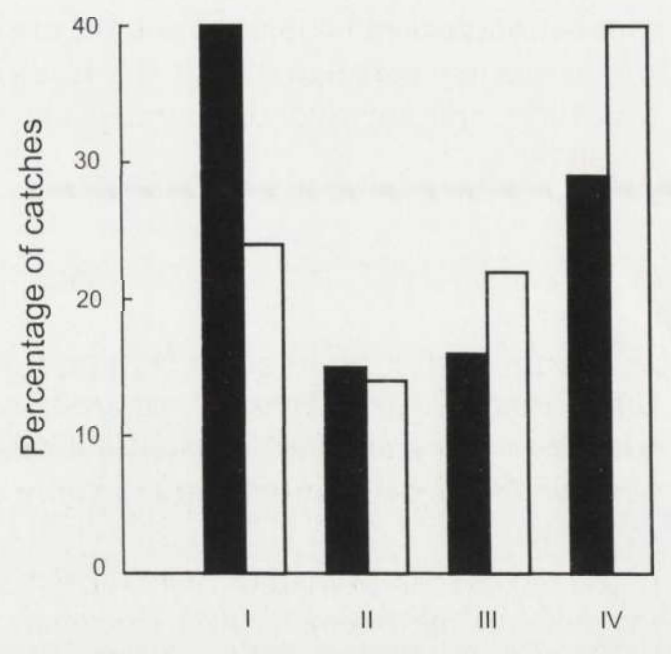

Table 2. Average distances (as measured by number of traps) between successive retraps on the same line of live-traps.

\begin{tabular}{lcc}
\hline $\begin{array}{l}\text { Successive } \\
\text { catches }\end{array}$ & $\begin{array}{c}\text { Number } \\
\text { of bank voles }\end{array}$ & Mean \pm SE \\
\hline $1-2$ & 82 & $24.4 \pm 19.6$ \\
$2-3$ & 71 & $4.1 \pm 7.5$ \\
$3-4$ & 47 & $3.8 \pm 6.4$ \\
$4-5$ & 34 & $3.0 \pm 6.4$ \\
$5-6$ & 22 & $2.2 \pm 1.8$ \\
$6-8$ & 14 & $1.8 \pm 1.3$ \\
\hline
\end{tabular}

Table 3. Average number of days between successive catches in live-traps.

\begin{tabular}{lcc}
\hline $\begin{array}{l}\text { Successive } \\
\text { catches }\end{array}$ & $\begin{array}{c}\text { Number } \\
\text { of bank voles }\end{array}$ & Mean \pm SE \\
\hline 1 & 117 & $4.8 \pm 2.6$ \\
2 & 75 & $2.7 \pm 1.7$ \\
3 & 48 & $2.0 \pm 0.9$ \\
4 & 34 & $1.5 \pm 0.8$ \\
5 & 22 & $1.4 \pm 0.5$ \\
$6-8$ & 14 & $1.4 \pm 0.6$ \\
\hline
\end{tabular}

$34.6 \%$ of individuals were caught the next day $(n=75)$. The longest period between the first and the next catch was 12 days (Table 3 ).

\section{Recaptures in snap-traps}

During the whole study, 114 marked bank voles first caught in live-traps and released at $\mathrm{R}$ were captured later in snap-traps. Of them, $92 \%$ were caught after the first release, and the remaining ones after the second or third release (Table 1).

The period between release of an animal in $R$ and then catching it in a snap-traps was analyzed, separately for the two types of bait used. It was found that the average period between release in $R$ and capture in a trap with sunflower oil was $5.2 \pm 2.8$ days and $3.2 \pm 1.6$ in a trap with odour bait (significant difference at $p<0.05$, Student's $t$-test). None of those values differed significantly from those for the period elapsed between the first and second catches in live-traps. The 
number of marked bank voles caught in snap-traps in consecutive days of the study was positively correlated with the total number of animals previously marked in the study, and not with the number marked on the previous day only $(r=0.7062$, $p=0.007)$.

\section{Discussion}

The following preliminary assumptions have been made: (1) bank voles have their "homes" (nest, burrow), where they come back to after each movement, also when returning after experimental displacement at some distance; (2) "homes" of bank voles are distributed rather evenly, providing there is sufficient homogeneity of the habitat.

It is well known that live-traps may constrain a range of small mammal movements (eg Sheppe 1967), however, they are indispensable to catch animals needed for homing experiments. Besides, using two lines $600 \mathrm{~m}$ apart instead of a grid of densely set traps considerably reduces the effect of live-traps on small mammal movements.

Live trap lines divided the area into two: the area between the two lines where snap-traps were set and $\mathrm{R}$ was located and the area outside the two lines. Bank voles that were caught could have their "homes" in either area. Thus, two logical modifications of the above patterns were possible: "in" and "out". According to "in" modification, an individual's "home" $(\mathrm{H})$ is located in the inner area (between the live trap lines), and according to "out" modification, "home" is located in the outer area (Fig. 3). Pattern I was recorded in $37 \%$ of cases. It is plausible that this pattern was typical for those animals which had "home" relatively close to the site of the first catch. The remaining $63 \%$ of the cases were consistent with patterns II and III providing that only the first two captures of each individual were taken into account (Fig. 4). Thus, a considerable proportion of bank voles were captured for the second time at a long distance from the first catch. When the second and subsequent captures were taken into account, pattern I predominated very clearly (only $3 \%$ of cases were consistent with pattern III).

A possible explanation for this pattern is that during extensive exploration of the area, bank voles found live-traps (source of food) that were at various distances from "home". If a trap was located close to "home", the animal behaved according to pattern I. If the trap found was far from home, the animal subsequently found a different trap closer to home (pattern II or III), and then regularly visited it as in pattern I. Sometimes finding a closer trap took place only after the second or later captures.

Subsequent visits to live-traps were subject to training. Voles found nearby traps more and more precisely and more frequently after subsequent captures. If their usual trap was already occupied or not working they entered one of several neighbouring traps (Table 2). As intervals between live-traps were small ( $6 \mathrm{~m}$ ), the neighbouring trap was really close. 
Another question is what caused the time to re-trapping to be so long (Table 3). Did an individual spend several days finding its way "home" from point R, or was it the delay between returning "home" and the next visit to a trap? So, what does the observed "training" really mean? Do voles become more efficient at finding their way between $R$ and "home", or between "home" and a nearby trap? The method used in our study allows for an indirect answer only.

Other authors have pointed to the role of training in homing (eg Teferi and Millar 1993), but they do not consider the above questions because they implicitly assumed "home" was very close to traps in which the individual was caught (within the grid of traps). The fact that the period between subsequent captures in live-traps was long in our study (Table 3) justifies the hypothesis that bank voles spend that time not on long search for "home" after release at R but instead, they come back home and then after some time visit certain nearby live-traps. The smaller and smaller number of traps visited and the increasing frequency of visits to traps in the course of the experiment were due to learning the route between $\mathrm{H}$ and $\mathrm{C} 2$ and not between $\mathrm{R}$ and $\mathrm{C} 2$ (Fig. 3).

The fact there is no significant correlation between the number of bank voles released at $\mathrm{R}$ on particular days of the experiment and the number of animals caught in snap-traps the next day suggests that animal movements revealed by catches in snap-traps are of within home range movements and not of homing character: animals passed traps rushing home. The fact that bank voles many times crossed lines with densely set snap-traps (every three meters) and were caught in live-traps after release in $\mathrm{R}$ indicates that those lines were not a vole proof barrier on the way between R and "home" (Table 1). As live-traps were more attractive than snap-traps (Fig. 2) they probably reduced efficiently the range of vole movements in the adjacent area. As a result, the trappability on lines of snap-traps located close to live trap lines was lower than that on lines closer to the point R. A considerable range of bank vole movements between lines of live-traps indicates that those traps were visited also by animals having their "home" at equally large distances outside those lines (modification "out" of spatial behaviour patterns).

Also, all cases of spatial behaviour consistent with pattern II (15\%) and especially with pattern III (45\%) suggest considerable range of movements. Such an extensive range of movements of voles could be the cause of considerable delay in visiting traps, especially when "out" variant occurred, and probably also the large number of individuals that were caught only once in live-traps $(64 \%, n=613)$.

The hypothesis that there are two fractions in a population: sedentary and migratory (Rall 1936 and a great body of more recent information) would be consistent with the following propositions: (1) individuals caught only once in live-traps would be dispersers traversing our study area, (2) voles caught on the trap line on one side of the point $R$ and then on the opposite side would be migrants that settled down in the neighbourhood of the second trap-line after the first catch (and thus show consecutive catches in similar locations).

The hypothetical picture of bank vole life in a homogeneous forest habitat seems to be the following: animals wander across large area where they find traps. If traps 
are provided with bait (food), animals visit them regularly. Thus, live-traps influence (direct and confine) spatial activity of bank voles. Extensive range of spatial activity and resulting familiarity with the area enables bank voles to return promptly after displacement and release at several hundred meters from "home" (homing). That is why homing efficacy depends on distance of displacement and maximal distances of small mammal homing are less than $2 \mathrm{~km}$ (Bovet 1978 and literature cited there). Especially large distances can be obtained in the case of movement pattern $\mathrm{R} \rightarrow \mathrm{H} \rightarrow \mathrm{C}$, when $\mathrm{R}$ and $\mathrm{C}$ are located at the farthest ends of the "life range". Then, a bank vole travels the longest possible way between $\mathrm{R}$ and $\mathrm{H}$ and the longest possible way between $\mathrm{H}$ and $\mathrm{C}$. In such a case a researcher obtains the sum of those two distances when calculating the distance between the points of release and a catch.

So, there is no need to search for any special mechanisms of homing like sun or magnetic "compass" (Saint Girons and Durup 1974, August et al. 1989). Our results confirm that small mammals commonly move at long distances (at least several hundred meters) and that mobility certainly contribute to their homing ability, no matter which hypothesis of homing is assumed as familiarity with the given area acquired during long distance movements is certainly helpful anyway. However, great mobility of rodents makes it impossible to reveal all long distance movements with traps set in grids of a standard size and therefore spatial organization of small mammal populations remains unclear.

\section{References}

Anderson P. K., Heinsohn G. E., Whitney P. H. and Huang J. P. 1977. Mus musculus and Peromyscus maniculatus: homing ability in relation to habitat utilization. Canadian Journal of Zoology 55: 169-182.

Andrzejewski R. and Babińska-Werka J. 1986. Bank vole population: are their densities really high and individual home range small? Acta Theriologica 31: 409-422.

Andrzejewski R. and Owadowska E. 1994. Use of odour bait to catch bank voles. Acta Theriologica 39: 221-225.

August P. V., Ayvazian S. G. and Anderson J. G. T. 1989. Magnetic orientation in small mammals. Journal of Mammalogy 70: 1-9.

Babińska-Werka J. 1990a. Response of rodent to an inceased and quantitatively diverse food base. Acta Theriologica 35: 151-156.

Babińska-Werka J. 1990b. Response of bank voles to a new source of food and its withdrawal. Acta Theriologica 35: 191-199.

Bovet J. 1978. Homing in wild myomorph rodents: current problems. [In: Animal migration, navigation and homing. K. Schmidt-Koenig and W. T. Keeton, eds]. Springer, Berlin: 405-412.

Bovet J. 1992. Mammals. [In: Animal homing. F. Papi, ed]. Chapman \& Hall, London: 321-361.

Bujalska G. 1973. The role of spacing behaviour among females in the regulation of reproduction in the bank vole. Journal of Reproduction and Fertility, Supplement 19: 463-472.

Bujalska G. 1985. Fluctuation in an island bank vole population in the light of the study on its organization. Acta Theriologica 30: 3-49.

Bujalska G. 1988. Life history consequences of territoriality in the bank vole. [In: Evolution of life histories of mammals. M. S. Boyce, ed]. Yale University Press, New Haven: 75-90. 
Bujalska G. 1990. Social structure and social organization in the bank vole. Wiadomości Ekologiczne 36: 188-202. [In Polish with English summary]

Clark B. K., Kaufman G. A., Finc E. J. and Hand S. S. 1988. Long-distance movements by Reithrodontomys megalotis in tallgrass prairie. American Midland Naturalist 120: 276-281.

Crawley M. C. 1969. Movements and home ranges of Clethrionomys glareolus Schreber and Apodemus silvaticus L. in north-eastern England. Oikos 20: 276-420.

Fisler G. F. 1967. An experimental analysis of orientation to the home sites in two rodent species. Canadian Journal of Zoology 45: 261-268.

Furrer R. K. 1973. Homing of Peromyscus maniculatus in the chanelled scablands of East-Central Washington. Journal of Mammalogy 54: 466-481.

Gashwiler J. S. 1959. Small mammal study in West-Central Oregon. Journal of Mammalogy 40: 128-139.

Grodziński W., Pucek Z. and Ryszkowski L. 1966. Estimation of rodent numbers by means of prebaiting and intensive removal. Acta Theriologica 11: 297-314.

Ilienko A. I. and Zubchaninova E. B. 1963. All year round observation of labeled Clethrionomys glareolus Shreb. and Apodemus sylvaticus L. in the localities near Moscow. Zoologicheskii Zhurnal 42: 609-617. [In Russian with English summary]

Joslin J. K. 1977. Rodent long distance orientation ("homing"). Advances in Ecological Research 10: 63-89.

Kozakiewicz M. and Szacki J. 1995. Movements of small mammals in a landscape: path restriction or nomadism? [In: Landscape approaches in mammalian ecology and conservation. W. Z. Lidicker Jr, ed]. University of Minnesota Press, Minneapolis: 78-94.

Lidicker W. Z. Jr and Patton J. L. 1987. Patterns of dispersal and genetic structure in populations of small rodents. [In: Mammalian dispersal patterns: The effects of social structure on population genetics. B. D. Chepko-Sade and Z. Tang Halpin, eds]. Chicago University Press, Chicago: 144-61.

Liro A. and Szacki J. 1987. Movements of field mice Apodemus agrarius (Pallas) in a suburban mosaic of habitats. Oecologia 74: 438-440.

Liro A. and Szacki J. 1994. Movements of small mammals along two ecological corridors in suburban Warsaw. Polish Ecological Studies 20: 223-227.

Murie O. J. and Murie A. 1931. Travels of Peromyscus. Journal of Mammalogy 12: 200-209.

Rall J. 1936. Characteristics of the movements of muride rodents within small plots. Zoologicheskii Zhurnal 15: 472-482. [In Russian with English summary]

Robinson W. L. and Falls J. B. 1965. A study of homing in the meadow mouse. American Midland Naturalist 73: 188-224.

Saint Girons M. C. and Durup M. 1974. Retour au gite chez le mulot Apodemus sylvaticus et le campagnol roussatre Clethrionomys glareolus. Facteurs ecologiques, apprentissage et memoire. Mammalia 38: 389-404.

Sheppe W. 1967. The effect of livetrapping on the movements of Peromyscus. American Midland Naturalist 78: 471-481.

Stickel L. F. 1968. Home range and travels. [In: Biology of Peromyscus (Rodentia). J. A. King, ed]. Special Publications of American Society of Mammalogists No 2: 373-411.

Szacki J. 1999. Spatially structured populations: how much do they match the classic metapopulation concept? Landscape Ecology 14: 369-379.

Szacki J., Babinska-Werka J. and Liro A. 1993. The influence of landscape spatial structure on small mammal movements. Acta Theriologica 38: 113-123.

Szacki J. and Liro A. 1991. Movements of small mammals in the heterogenous landscape. Landscape Ecology 5: 219-224.

Teferi T. and Millar J. S. 1993. Long distance homing by the deer mouse, Peromyscus maniculatus. The Canadian Field Naturalist 107: 109-111.

Tew T. 1988. The ecology of the European wood mouse (Apodemus sylvaticus) on British farmland. Abstracts of 2nd International Behaviour Ecology Conference, Vancouver: 103.

Received 5 July 1996, revised 26 November 1999, accepted 21 December 1999. 